\title{
The Vital-IT HPC and the Swiss-Prot group
}

\section{Laurent Falquet}

Vital-IT, Swiss Institute of Bioinformatics, Genopode-UNIL, Lausanne, Switzerland http://www.vital-it.ch/

Biomedical research requires increasing computing power to analyse the huge amounts of data researchers accumulate using high-throughput technologies. However computing power itself is not sufficient, the joint knowledge and expertise of qualified bioinformaticians, statisticians, and IT specialists is essential to provide an efficient support to large-scale projects in biology. Vital-IT is a High Performance Center dedicated to support biological projects within Switzerland. In conjunction with the Swiss-Prot group in Geneva, it forms a unique entity providing both infrastructure and a set of experts in all fields required by modern biology projects. A few examples of genome assembly projects are presented.

\section{References}

1. Wurm et al., The genome of the fire ant Solenopsis invicta. PNAS 2011 Apr 5;108(14):5679-84. PMID: 21282665.

2. Andres-Barrao et al., Genome sequences of the high-acetic acid-resistant bacteria Gluconacetobacter europaeus LMG 18890T and G. europaeus LMG 18494 (reference strains), G. europaeus 5P3, and Gluconacetobacter oboediens 174Bp2 (isolated from vinegar). J Bacteriol. 2011 May;193(10):2670-1. PMID: 21441523.

3. Calderon et al., The Mycoplasma conjunctivae genome sequencing, annotation and analysis. BMC Bioinformatics. 2009 Jun 16;10 Suppl 6:S7. PMID: 19534756.

\section{Relevant Web sites}

4. http://www.vital-it.ch/

5. http://www.isb-sib.ch/ 